
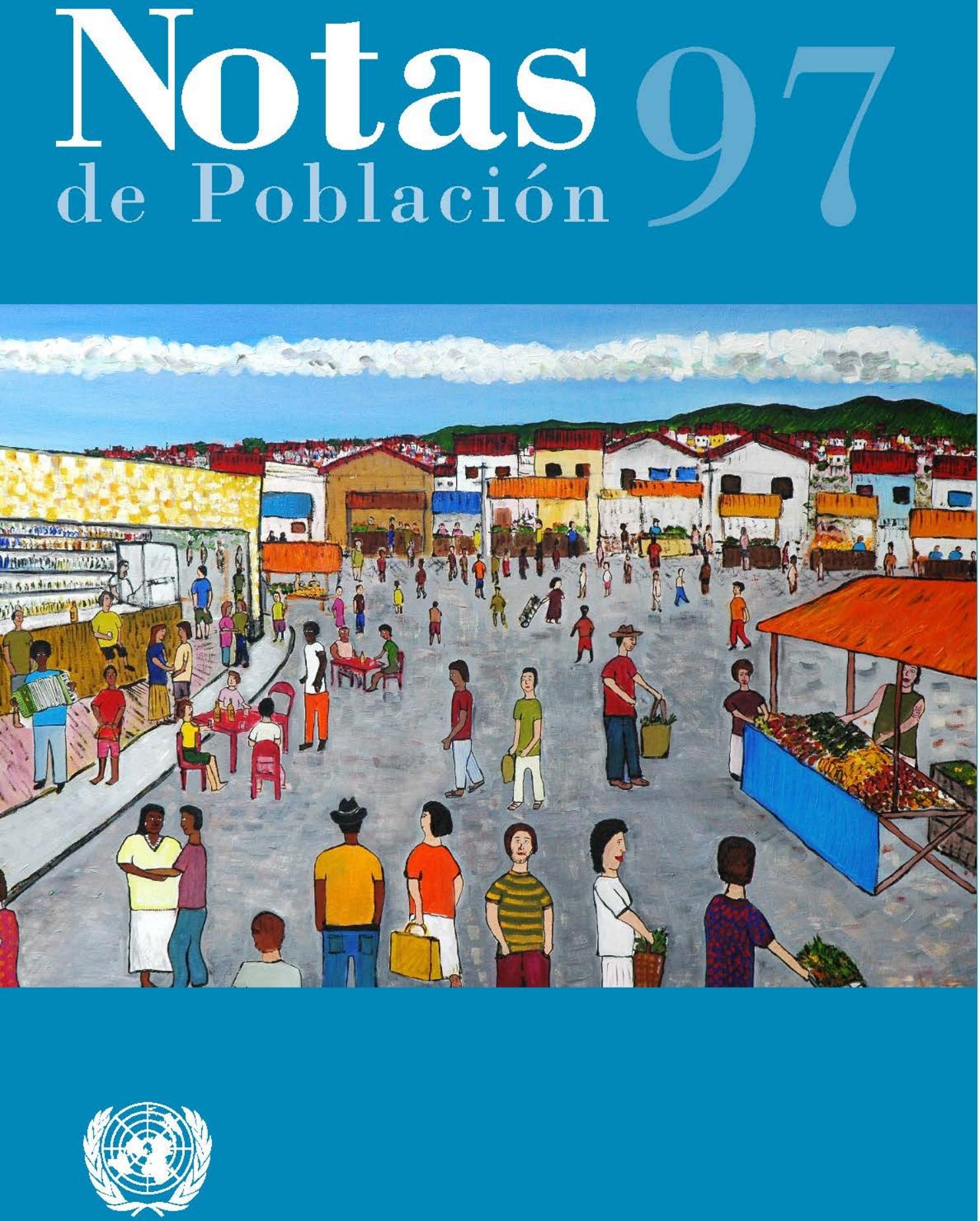

NACIONES UNIDAS

CEPA L

Comisión Económica para América Latina y el Caribe • CEPAL Centro Latinoamericano y Caribeño de Demografía • CELADE 


\author{
Alicia Bárcena \\ Secretaria Ejecutiva \\ Antonio Prado \\ Secretario Ejecutivo Adjunto \\ Dirk Jaspers_Faijer \\ Director, Centro Latinoamericano y Caribeño de Demografía \\ (CELADE)-División de Población de la CEPAL
}

Ricardo Pérez

Director, División de Publicaciones y Servicios Web

La revista Notas de Población es una publicación del Centro Latinoamericano y Caribeño de Demografía (CELADE)-División de Población de la CEPAL, cuyo propósito principal es la difusión de investigaciones y estudios de población sobre América Latina y el Caribe, aun cuando recibe con particular interés artículos de especialistas de fuera de la región y, en algunos casos, contribuciones que se refieren a otras regiones del mundo. Se publica dos veces al año, con una orientación interdisciplinaria, por lo que acoge tanto artículos sobre demografía propiamente tal como otros que aborden las relaciones entre las tendencias demográficas y los fenómenos económicos, sociales y biológicos. Las opiniones expresadas en esta revista son responsabilidad de los autores, sin que el Centro Latinoamericano y Caribeño de Demografía (CELADE)-División de Población de la CEPAL, sea necesariamente partícipe de ellas. Los límites y los nombres que figuran en los mapas de esta publicación no implican su apoyo o aceptación oficial por las Naciones Unidas.

\title{
Comité editorial:
}

Ciro Martínez Gómez, Coordinador

María Isabel Cobos, Editora especial

Alejandra Silva, Guiomar Bay, Fabiana del Popolo, Sandra Huenchuan,

Dirk Jaspers_Faijer, Jorge Martínez Pizarro, Timothy Miller, Jorge Rodríguez, Magda Ruiz, Paulo Saad, Miguel Villa, Orly Winer

Liliana Cuevas, secretaria

Redacción y administración: Casilla 179-D, Santiago, Chile. E-mail: liliana.cuevas@cepal.org Ventas: publications@cepal.org. Precio del ejemplar: 12 dólares. Suscripción anual: 20 dólares. 


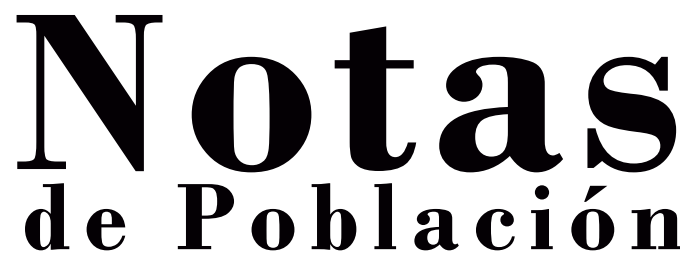

Año XL • No $97 \bullet$ Santiago de Chile

NACIONES UNIDAS 
Este número contó con el apoyo financiero del Fondo de Población de las Naciones Unidas (UNFPA).

Los límites y los nombres que figuran en estos mapas no implican su apoyo o aceptación oficial por las Naciones Unidas.

Diseño de portada: Alejandro Vicuña Leyton

Ilustración de portada: Forro na feira, acrílico sobre tela de Cristiano Sidoti. Colaboración de: Galería Jaques Ardies, São Paulo (Brasil). Derechos reservados

Publicación de las Naciones Unidas

ISBN: 978-92-1-121837-4

E-ISBN: 978-92-1-056241-6

ISSN: 0303-1829

LC/G.2598-P

Número de venta: S.13.II.G.14

Copyright (C) Naciones Unidas 2013 • 2013-572

Todos los derechos reservados. Impreso en Naciones Unidas, Santiago de Chile

La autorización para reproducir total o parcialmente esta obra debe solicitarse al Secretario de la Junta de Publicaciones, Sede de las Naciones Unidas, Nueva York 10017, Estados Unidos. Los Estados miembros y sus instituciones gubernamentales pueden reproducir esta obra sin autorización previa. Solo se les solicita que mencionen la fuente e informen a las Naciones Unidas de tal reproduccción. 


\section{Índice}

Fecundidad fuera de la unión en el Paraguay .................................. 7

Emily Vala-Haynes

Claudia Valeggia

Hans-Peter Kohler

La maternidad adolescente en el contexto de la migración internacional: el caso de Costa Rica ..................................................

Heidi Ullmann

Estimación de la mortalidad materna sobre la base de la información censal: experiencias y perspectivas

Magda Ruiz

Mortalidad en la niñez en la Argentina: disparidades regionales y sociales frente a la cuarta meta del Milenio.

Juan Carlos Cid

Jorge A. Paz

Políticas públicas y migración interna en la República

Bolivariana de Venezuela contemporánea.

Ana Julia Allen

Una metodología para la estimación de la emigración

internacional a partir del registro administrativo

de control de fronteras de Migración Colombia

Joaquín Recaño Valverde

Carolina Sánchez Barriga

Vivian Natalia Rivera Sepúlveda 
Pueblos indígenas y afrodescendientes en los censos de población y vivienda de América Latina: avances y desafíos en el derecho a la información 205 Fabiana Del Popolo

Susana Schkolnik

Estudio comparativo de la vitalidad lingüística de 14 pueblos de Colombia realizado mediante una encuesta (autodiagnóstico sociolingüístico) 249

Yolanda Bodnar $C$. 


\title{
Políticas públicas y migración interna en la República Bolivariana de Venezuela contemporánea
}

\author{
Ana Julia Allen
}

\begin{abstract}
Resumen
Las transformaciones del aparato productivo, los cambios en la economía global y ciertos factores políticos y sociales han configurado diversos patrones de movilidad territorial. El interés de esta investigación se centra en analizar las tendencias de la migración interna en la República Bolivariana de Venezuela desde 1971 hasta 2001. Sobre la base de la información suministrada por los censos de población y vivienda se elaboraron matrices de origen y destino multirregionales que permitieron identificar la direccionalidad de los flujos y establecer áreas tradicionales y emergentes de atracción y expulsión. La regionalización, construida a partir del índice de desarrollo humano, permitió distinguir corrientes migratorias entre regiones de alto, medio y bajo desarrollo humano, que evidencian la desigual distribución de las actividades productivas dentro del territorio nacional. Finalmente, el análisis de los resultados en el marco de los procesos histórico-estructurales demostró el vínculo que existe entre las decisiones políticas, la activación económica de los territorios y la dinámica migratoria interna.
\end{abstract}

\begin{abstract}
Transformations in the production apparatus, changes in the global economy and certain political and social factors have given rise to various patterns of territorial mobility. This paper analyses trends in internal migration in the Bolivarian Republic of Venezuela from 1971 to 2001. On the basis of information from national population and housing censuses, multiregional origin-destination matrices were established identifying the direction of migration flows and traditional and emerging push and pull factors of migration. Using the human development index, migratory flows between regions of high, medium and low levels of human development were determined, therefore demonstrating the uneven distribution of production activities in the country. Lastly, the results were analysed in the context of historical and structural processes, showing the link between policy decisions, each region's economic emergence and the dynamics of internal migration.
\end{abstract}




\section{Résumé}

Les transformations de l'appareil de production, les changements de l'économie mondiale et certains facteurs politiques et sociaux ont déterminé différents modèles de mobilité territoriale. Cette recherche est centrée sur l'analyse des tendances de la migration interne dans la République bolivarienne du Venezuela entre 1971 et 2001. Sur la base de l'information issue des recensements de la population et du logement, l'auteure a élaboré des matrices d'origine et de destination multirégionales qui ont permis de définir le sens des flux de population ainsi que les zones traditionnelles et émergentes d'attraction et d'expulsion. La régionalisation, construite à partir de l'indice de développement humain, a permis de distinguer des flux migratoires entre des régions à développement humain élevé, moyen et faible, qui rendent compte de la distribution inégale des activités productives au sein du territoire national. Finalement, l'analyse des résultats à la lumière des processus historiques et structurels démontre qu'il existe un lien entre les décisions politiques, l'activation économique des territoires et la dynamique migratoire interne. 


\section{Introducción}

Existen múltiples alternativas para resolver los asuntos públicos. No obstante, la evolución del pensamiento político ha reconocido diferentes modalidades de acción de acuerdo con la ideología dominante en tiempos y espacios determinados. La teoría moderna define las políticas públicas como "cursos de acción y flujo de información relacionados con un objetivo público definido en forma democrática; los que son desarrollados por el sector público y frecuentemente con la participación de la comunidad y el sector privado" (Lahera, 2002, pág. 16). Pero esta definición solo se ajusta a los cánones modernos. Hubo tiempos en que se aplicaron políticas definidas bajo una modalidad de Estado paternalista, dominadas por el pensamiento económico y con escasa o nula participación ciudadana, que fueron determinantes para la configuración de los destinos nacionales.

Cualquier abordaje histórico que no reconozca estas transformaciones conceptuales del pensamiento moderno corre el riesgo de traducir la realidad de manera sesgada. Atentos a este peligro, consideramos necesario adoptar una definición neutral de la expresión "políticas públicas" que contribuyera a identificar ciertas acciones gubernamentales como política y que, además, se ajustara a diferentes contextos y espacios temporales. La interpretación de Manuel Alcántara resultó bastante congruente con nuestros objetivos: "determinados flujos del régimen político hacia la sociedad, que son productos del sistema político y por tanto del uso estratégico de recursos para enfrentar los problemas nacionales" (Alcántara, 1995, citado en González Tachiquin, 2005, pág. 109).

De acuerdo con esta definición, las políticas no surgen de manera espontánea, sino que son el resultado objetivo de la articulación de una serie de componentes que operan dentro de un entorno social específico. Los "flujos del régimen político hacia la sociedad" son los cursos de acción que emprende un gobierno para solucionar los problemas nacionales, incluidos los procesos de formulación e implementación de políticas. Dependiendo de la modalidad de intervención, las políticas públicas pueden dividirse en políticas de acción directa, que actúan de manera explícita sobre el problema-objeto que se desea solucionar, y políticas de acción indirecta, que son programas creados con fines diferentes al problema-objeto, pero que igualmente presentan efectos colaterales sobre él. Esto sugiere que todo cambio económico, tecnológico, institucional o de otro tipo que se efectúe dentro de los 
límites del sistema político puede tener consecuencias directas o indirectas sobre las diferentes dimensiones de la realidad social.

Los efectos de las políticas no pueden medirse en su totalidad. Cualquier intervención pública redunda en una alteración del estado natural de las cosas que puede originar impactos a corto, mediano o largo plazo (Meny y Thoenig, 1992). ¿Cómo es posible cuantificar todos estos resultados? Hoy en día, la evaluación de las políticas públicas es prácticamente una obligación. Sin embargo, cuando la mirada se vuelve hacia al pasado, se encuentra un conjunto de escenarios y circunstancias apuntadas por la historia, un agregado de datos estadísticos archivados en los registros nacionales, una lista resumida de acciones, medidas y decisiones de cada uno de los gobiernos de turno, y solo queda utilizar la lógica racional para tratar de enlazar todos esos elementos en una historia coherente.

Entre el conjunto de acciones que puede tomar un gobierno, la política económica suele tener un lugar preponderante por estar implícitamente asociada a la riqueza y el bienestar de las naciones. Durante gran parte del siglo XX, la doctrina desarrollista se conjugó con el mundo político, especialmente en aquellos países conocidos como "periféricos", que buscaban las maneras de replicar las condiciones económicas de los países tecnológicamente más avanzados. En medio de este entorno ideológico, los gobiernos dictaron una serie de medidas dirigidas a impulsar los procesos de industrialización y modernización, que sin duda impactaron en la estructura social y las relaciones entre los espacios nacionales.

La modernización conlleva la modificación del espacio físico. Sin embargo, estas transformaciones no se ejecutaron de manera homogénea. En las estrategias que adoptaron los líderes nacionales por lo general se privilegiaron algunos territorios por encima de otros. El criterio no fue muy diferente de la lógica colonialista forjada en el pasado; mientras las ciudades tradicionalmente constituidas se convertían en grandes metrópolis, otros espacios de los territorios nacionales permanecieron rezagados de los procesos modernizadores. El resultado fue una agudización de las disparidades territoriales, que degeneraron en renovados escenarios de desigualdad social.

Toda esta trama teórica brinda el preámbulo conceptual al problema que nos ocupa: la migración interna en la República Bolivariana de Venezuela. La idea es examinar, sobre la base de la historia política venezolana y de los datos extraídos de los censos nacionales, qué efectos directos o indirectos pudieron tener las políticas públicas implementadas por los diferentes gobiernos sobre la direccionalidad de 
las corrientes migratorias internas y cuál ha sido la intensidad de dicha movilidad territorial, a partir de la instauración de la democracia, en 1958. Aunque en algunos estudios se ha tratado de esclarecer dichos temas, las aproximaciones a los diversos aspectos se han hecho de manera parcial o independiente. En este trabajo, en cambio, se busca vincular en una sola línea argumentativa cuatro dimensiones de la realidad migratoria: i) la direccionalidad e intensidad de la migración reciente, ii) la noción de desarrollo regional, iii) la visión histórica y iv) la visión política.

La gran ventaja de un estudio de tipo histórico es que proporciona una línea temporal que no solo permite acercarse el pasado, sino también contextualizar y entender la dinámica migratoria del presente. Por último, es importante aclarar que aunque el propósito es vincular datos estadísticos con procesos económicos y políticos, no se busca establecer relaciones de manera determinista. La línea argumentativa que subyace es que la presencia o la ausencia de políticas - en un momento y espacio determinados - pueden generar contextos favorables o desfavorables para la migración.

\section{A. Aspectos metodológicos}

Tres son las fuentes directas de información sobre los procesos de movilidad territorial: el censo, los registros y las estadísticas vitales. El empadronamiento censal, al ser una herramienta de cobertura universal, es la fuente que mejor recoge la información sobre migraciones. En la República Bolivariana de Venezuela, las investigaciones referentes a la migración interna se han abordado a partir de las preguntas sobre lugar de nacimiento y duración de la residencia actual, incorporadas en el formulario censal desde 1950, y sobre lugar de residencia anterior, incluida a partir de 1961.

La variable "lugar de la última residencia" combinada con "duración de la residencia actual" permite captar la migración reciente. Este tipo de medición - al establecer un período de tiempo definidohace posible la estimación de tasas de migración, la determinación de la población expuesta al riesgo de migrar y la definición de corrientes migratorias acordes con el momento histórico. En este estudio se consideró únicamente la migración reciente, obtenida a partir de los datos suministrados por los últimos cuatro empadronamientos levantados y publicados en la República Bolivariana de Venezuela. 
La forma de indagar la duración de la residencia actual en los formularios censales nacionales ha variado con el tiempo. Hasta 1990 se preguntó: “¿hace cuánto tiempo reside (o [cuánto tiempo] tiene viviendo) en este municipio (o entidad, ciudad, centro poblado)?” Entre 1971 y 1990 solo se modificó la escala geográfica en la que se registró el acto migratorio. A partir del censo de 2001, esta modalidad se transformó radicalmente y se estableció una fecha de referencia fija, incluida en la pregunta: "¿en cuál municipio y estado residía en octubre de 1996?"

Aun cuando los dos tipos de preguntas no responden a la duración de la residencia en los mismos términos, ambos permiten cuantificar movimientos migratorios recientes. Por convención, se ha aceptado circunscribir la pregunta sobre "duración de la residencia actual" a una fecha intermedia entre dos empadronamientos sucesivos, es decir, cinco años antes de la aplicación del censo. Si se advierten las dificultades que implica un cambio definitivo de residencia en un corto período de tiempo, es posible sostener que mientras menor es el lapso temporal entre el cambio de residencia y el levantamiento censal, menor es la posibilidad de ocurrencia de movimientos migratorios múltiples (Partida, 2011). De esta manera, para efectos de esta investigación, se supondrá que en cada quinquenio se produjo un único movimiento migratorio o ninguno. Con este supuesto, la información obtenida por ambos procedimientos es comparable en mayor medida.

Sobre la base de este criterio, se consideró migrantes a todas las personas que al momento del censo: i) declararon haber cambiado de región de residencia durante el quinquenio anterior al empadronamiento (en los censos de 1971, 1981 y 1990), o ii) indicaron haber residido cinco años atrás en una región distinta a aquella en que eran empadronados (en el censo de 2001) ${ }^{1}$. Cabe precisar que, a diferencia de los censos anteriores, en este último empadronamiento la sección sobre migración estuvo dirigida a personas de 3 años de edad o más. Para garantizar la máxima comparabilidad entre los datos, y teniendo presente que la migración de toda la vida para un niño de 3 años probablemente no presente la dificultad de tener que agrupar varios movimientos en un lapso restringido de tiempo, se decidió para todo menor de 3 años residente en un lugar diferente al de nacimiento, considerar la variable "lugar de nacimiento" como lugar de residencia anterior.

Esta definición de migrantes excluye los cambios de residencia intrametropolitanos. La movilidad territorial dentro de las áreas conurbadas

Las personas migrantes que no declararon la entidad de residencia anterior o que indicaron que residían en el exterior fueron descartadas del análisis. 
no se ajusta totalmente a la lógica de la migración interna. La expansión de las grandes ciudades dificulta la determinación de límites espaciales dentro del mercado inmobiliario, el mundo laboral y la actividad social. Debido a la imposibilidad de definir un marco geográfico de referencia dentro del entorno de interacción social, los cambios de residencia dentro de la metrópoli no constituyen grandes modificaciones en los patrones de movilidad cotidiana. Considerando los elementos teóricos de este debate, se descartó la movilidad intrametropolitana de la diagonal principal para todas las matrices.

En la República Bolivariana de Venezuela existe una única zona metropolitana autónoma y con personalidad jurídica, de acuerdo con las leyes nacionales. El Área Metropolitana de Caracas está conformada por cinco municipios: el municipio Bolivariano Libertador del Distrito Capital y los municipios Baruta, Chacao, El Hatillo y Sucre, pertenecientes al estado Bolivariano de Miranda. La información sobre movilidad territorial entre estas áreas fue extraída de la diagonal principal de la matriz de origen y destino, en la medida de lo posible ${ }^{2}$.

El análisis de los datos censales se hizo a partir de la construcción de matrices de origen y destino multirregionales. Con este tipo de arreglo matricial bivariado entre lugares de origen y destino, se pudo tener un panorama más preciso de las tendencias de movilidad territorial y la evolución de las corrientes migratorias. Finalmente, al usar la misma unidad temporal en todos los censos, fue posible la construcción de tasas que mostraran el efecto de los movimientos migratorios, tanto de entradas como de salidas, sobre los totales poblacionales regionales.

Como parte de la evaluación de la calidad de los datos, se verificó que los análisis de las matrices de origen y destino no estuviesen condicionados por errores de omisión. Al revisar la proporción en que no había respuesta para las preguntas sobre migración, en función del total poblacional, se observó un alto porcentaje en el censo de 1971, ya que al menos 24 personas de cada 100 no contestaron las preguntas asociadas al tema migratorio. No obstante, a partir de 1981 se advirtió una notable disminución de este porcentaje, que nunca volvió a ser superior a un dígito. El porcentaje de falta de respuesta fue del 3,5\%

2 En los censos de 1971, 1981 y 1990 no se recogió la pregunta sobre "lugar de residencia anterior" a nivel de municipios, lo que dificulta la estimación de la movilidad intrametropolitana. Sin embargo, como el Distrito Capital comprende un solo municipio, fue posible calcular los empadronados en los municipios Baruta, Chacao, El Hatillo y Sucre que durante los quinquenios anteriores a cada censo se movilizaron hacia el municipio Bolivariano Libertador. En el caso del censo de 2001, como todas las preguntas sobre migración se hicieron a escala municipal, pudieron estimarse los flujos en ambas direcciones sin problemas. 
en el censo de 1981, se incrementó al 5,4\% en 1990 y alcanzó un valor mínimo del 2,2\% en 2001. Esto sugiere que los resultados obtenidos son bastante aproximados a la realidad migratoria nacional. A partir de esta información, se decidió no considerar la ausencia de respuesta dentro del análisis de las matrices.

\section{B. Una regionalización construida desde el desarrollo}

Con la idea de facilitar el análisis de la información migratoria, se propuso dividir el espacio geográfico nacional en dimensiones más amplias que los estados, con características comunes. Las regiones se definieron en función del índice de desarrollo humano (IDH) de cada estado correspondiente a 2008.

Como la clasificación tradicional del IDH propuesta por el Programa de las Naciones Unidas para el Desarrollo (PNUD) no se ajustaba a la realidad venezolana, se realizó una nueva sistematización del índice. Considerando los valores mínimos y máximos de los IDH reportados, se aplicó un algoritmo para clasificar los estados en cinco nuevas categorías de desarrollo: (1) muy bajo, (2) bajo, (3) medio, (4) alto y (5) muy alto.

Clasificados los estados, se inició el proceso de conformación de las áreas regionales. Como se sabe, la gran variedad de características biofísicas de los paisajes nacionales y las formas históricas de organización de los espacios territoriales constituyen diversos escenarios geográficos y socioeconómicos, que pueden resultar difíciles de conciliar y, ciertamente, al momento de agrupar los estados de acuerdo con la clasificación establecida, se presentaron incongruencias geográficas y algunos quedaron aislados. Sin embargo, respetando la cercanía geográfica y considerando el IDH se logró establecer seis regiones. En algunos casos, se unificaron estados con niveles del IDH bajos y muy bajos o medios. En otros, se agruparon estados con niveles del IDH altos y muy altos. Pero nunca se combinaron niveles del IDH altos con niveles medios o bajos, para no ir en contra del argumento central sobre la existencia de brechas de oportunidades entre zonas de mayor y menor IDH. Las regiones quedaron constituidas como se muestra en el mapa 1. 


\section{Mapa I \\ REPÚBLICA BOLIVARIANA DE VENEZUELA: REGIONES DEFINIDAS SEGÚN NIVELES DEL ÍNDICE DE DESARROLLO HUMANO (IDH) DE LOS ESTADOS}

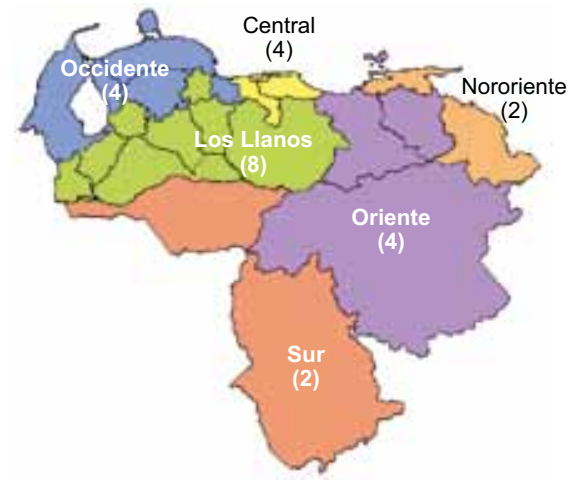

Fuente: Elaboración propia.

- Región central: se encuentra conformada por el Distrito Capital, el estado de Aragua, el estado Bolivariano de Miranda y el estado de Vargas. Ocupa parte de la cordillera Central, que bordea el mar Caribe. Su área presenta una densidad poblacional de 389,4 habitantes por $\mathrm{km}^{2}$. Esta región alberga el centro administrativo del gobierno central y concentra gran parte de la actividad industrial. Este grupo de entidades exhibe los índices de desarrollo humano más altos del país.

- Región occidente: comprende los estados de Carabobo, Falcón, Lara y Zulia. Constituye el $12,3 \%$ del territorio nacional y tiene una densidad poblacional de 76,7 habitantes por $\mathrm{km}^{2}$. En la región se desarrollan tres tipos de actividades económicas, la explotación petrolera, la producción industrial y el comercio. Todos estos estados presentan un alto nivel de desarrollo humano.

- Región de Los Llanos: abarca los estados de Barinas, Cojedes, Guárico, Mérida, Portuguesa, Táchira, Trujillo y Yaracuy. Su superficie comprende parte de la cordillera oriental de Los Andes, los llanos occidentales y los llanos centrales. Representa el 18,3\% del territorio nacional y exhibe una densidad poblacional de 36,1 habitantes por $\mathrm{km}^{2}$. Las actividades económicas principales son la agricultura y la ganadería. En esta región coinciden estados con índice de desarrollo humano medio y bajo. Sin embargo, la distancia entre los estados de mayor y de menor índice es de apenas 0,0408.

- Región oriente: agrupa los estados de Anzoátegui, Bolívar, Monagas y Nueva Esparta. Abarca desde la región insular hasta el macizo 
guayanés. Representa el 34,3\% del territorio nacional y tiene una densidad poblacional de 13,6 habitantes por $\mathrm{km}^{2}$. La producción petrolera, la siderurgia, el turismo y el comercio son las actividades económicas características de esta región. Todos los estados presentan altos índices de desarrollo humano.

- Región nororiente: está conformada únicamente por los estados de Delta Amacuro y Sucre. Limita al norte con el mar Caribe y alberga el delta del río Orinoco. Representa el 5,7\% del territorio nacional y tiene una densidad poblacional de 20,4 habitantes por $\mathrm{km}^{2}$. Su actividad económica predominante es la pesca. En cuanto al desarrollo humano, Delta Amacuro se ubica en el nivel más bajo de la clasificación y Sucre un grado más alto (IDH bajo), con una diferencia de 0,0122.

- Región sur: reúne los estados de Amazonas y Apure, y comprende la mayor extensión de los llanos bajos venezolanos y gran parte del escudo guayanés y la selva amazónica. Aunque representa el 27,7\% del territorio nacional, tiene una densidad poblacional de apenas 2,4 habitantes por $\mathrm{km}^{2}$. En esta región predominan las actividades agropecuarias y sus estados son los que presentaron los índices de desarrollo humano más bajos de todo el país.

Las regiones que presentan índices de desarrollo humano medios y bajos tienen en común un alto componente rural. En 1971, la población rural representaba un $52,1 \%$ en la región sur, un $38,8 \%$ en la región de Los Llanos y un 36,3\% en la región nororiente. En 2001, estos porcentajes habían disminuido sustancialmente. Sin embargo, en comparación con las regiones de alto nivel de desarrollo, la población rural de estas regiones siguió siendo significativa: en la región sur alcanzaba una proporción del $30 \%$, en la región de Los Llanos del $22,6 \%$ y en la región nororiente del $19,2 \%$. Aunque estas regiones no hayan sido predominantemente rurales, estos altos porcentajes, en especial en los contextos migratorios de los años setenta y ochenta, permiten suponer un tipo de movilidad rural-urbana.

Sin embargo, esta suposición no es suficiente para sostener que los flujos iniciados en estas u otras regiones hayan sido del tipo rural-urbano, urbano-urbano o urbano-rural. En este punto, la síntesis que se consigue con la regionalización representa una dificultad que quizás pueda ser superada desde la racionalidad teórica. De acuerdo con múltiples estudios sobre migración interna en América Latina (Muñoz y De Oliveira, 1972; Freitez, 1988; Chávez Galindo, 1999; Rodríguez y Busso, 2009), históricamente la migración rural-urbana ha presentado cierta selectividad, en particular una predominancia de movilidad femenina, que ha sido atribuida "a los espacios laborales específicos que ocupan las mujeres migrantes en las 
ciudades, como en el sector servicios o en el empleo doméstico" (Rodríguez y Busso, 2009, pág. 45). Por lo tanto, con el propósito de no perder debido a la regionalización un elemento fundamental del análisis histórico como es el tipo de migración, se recurrirá a este argumento teórico para sostener que los flujos que presenten tasas migratorias discriminadas por sexo que sean mayores en el caso de las mujeres, entre áreas no predominantemente urbanas, son movimientos de tipo rural-urbano.

\section{Lo que cuenta la historia y lo que dicen los datos}

La migración es un fenómeno de vieja data. Sin embargo, no fue sino hasta el siglo XX cuando la República Bolivariana de Venezuela comenzó a experimentar movimientos masivos. La producción de petróleo transformó la economía nacional y modificó las formas tradicionales de ocupación territorial. La localización de las principales ciudades no varió tanto como la concentración de la población urbana, en especial en la franja norte costeña-montañosa del país, donde tradicionalmente se situaron los mayores asentamientos.

Entre 1920 y 1940, los fondos obtenidos de la renta petrolera fortalecieron la capacidad del Estado, permitiendo la aplicación de una serie de políticas que repercutieron sobre los procesos de movilidad territorial. Estos y otros factores impulsaron la histórica pérdida de población de las áreas rurales nacionales, junto con el despegue del crecimiento urbano, principalmente en la ciudad capital. La actividad petrolera también generó nuevos polos de atracción, que otorgaron dirección a las corrientes migratorias. El éxodo campesino marcó un hito en la historia contemporánea venezolana, debido a la intensidad de la movilidad.

El golpe de Estado de 1948 abrió paso al régimen militar del general Marcos Pérez Jiménez. La dictadura emprendió una serie de proyectos dirigidos hacia la reestructuración y la modernización de los espacios físicos regionales. Se vinculó la noción de desarrollo al proceso de modernización. El 23 de enero de 1958 fue derrocada la dictadura y en 1959 Rómulo Betancourt asumió la presidencia, instaurándose así la democracia en Venezuela.

\section{Los años sesenta: ¡compre venezolano!}

Durante el período de gobierno de Betancourt, los precios del petróleo cayeron. La disminución del ingreso fiscal demostró que el peso de las importaciones era insostenible para la economía nacional. Los dirigentes 
vieron en la industrialización la solución adecuada para desarrollar sectores económicos, y fue así como el gobierno nacional se sumó a la propuesta de la Comisión Económica para América Latina (CEPAL) de industrialización por sustitución de importaciones.

Las reformas más sustanciales estuvieron dirigidas hacia la estructura de la tenencia de la tierra. En 1960, el Ejecutivo aprobó la Ley de Reforma Agraria, política que fracasó y operó de manera contraproducente, estimulando la depresión del sector agrícola (Suárez y Torrealba, 1979). Por su parte, la reforma agrícola ideada con el objetivo de aumentar la producción y fomentar el desarrollo capitalista del campo tuvo mayor éxito. Sin embargo, la incorporación de alta tecnología desfavoreció la demanda de mano de obra campesina, afectando la situación del campo venezolano.

La frase "compre venezolano" fue la consigna del gobierno de Rómulo Betancourt. Se pensaba que la política industrial no solo liberaría al país de la dependencia petrolera, sino que también generaría nuevas fuentes de empleo y maximizaría el aprovechamiento de los recursos naturales. Una parte considerable del presupuesto nacional se dirigió al financiamiento de la industria.

Caracas, por el hecho de ser el principal centro de consumo, disponer de más mano de obra y ser la sede del gobierno central, indujo la localización espacial de la actividad industrial en sus alrededores. No obstante, la ciudad capital presentaba la limitación de no contar con terrenos planos donde pudiera tener lugar un mayor desarrollo de infraestructura productiva. Para aliviar el problema del espacio, surgió la idea de crear zonas satélites que permitieran establecer un eje industrial en conjunto con capitales regionales vecinas (Barrios, 2008). Las capitales de los estados de Aragua y Carabobo se convirtieron en las sedes principales de los parques industriales levantados en el centro del país. El crecimiento económico de esta región generó una alta capacidad de empleo, que estimuló la atracción de migrantes.

\section{Primer momento: el panorama de la migración en el censo de 197I}

En medio de este contexto, en 1971 se realizó el X Censo de Población y Vivienda. El empadronamiento registró un total de 10.721.522 habitantes, de los cuales 807.178 declararon haber cambiado de lugar de residencia en los cinco años anteriores, es decir, un 7,53\% de la población total fue parte del fenómeno migratorio dentro de los límites nacionales entre 1966 y 1971.

Las regiones más dinámicas en este período fueron las regiones central y occidente, como zonas de atracción, y la región de Los Llanos, 
como zona de expulsión (véase el mapa 2). Las áreas de mayor concentración industrial resultaron ser las más atractivas y captaron la llegada de personas de regiones económicamente más frágiles, es decir, las regiones nororiente, de Los Llanos, sur y oriente.

\section{Mapa 2}

\section{VENEZUELA: FLUJOS MIGRATORIOS INTERREGIONALES, I 97 |}

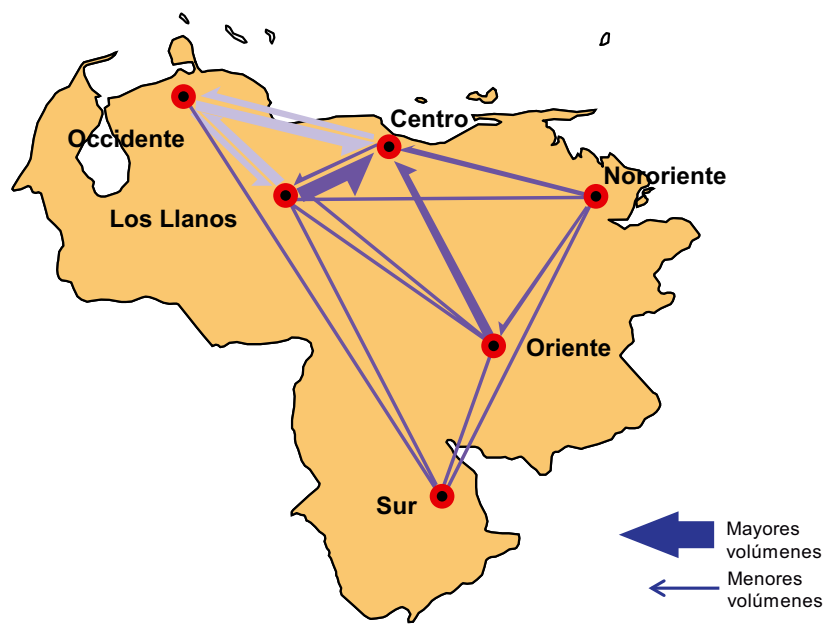

Fuente: Elaboración propia, sobre la base de los datos del X Censo de Población y Vivienda de 1971.

En términos porcentuales, la matriz de la estructura migratoria muestra que la mayor proporción de movimientos se concentró dentro de la región central (véase el cuadro 1). De acuerdo con la información censal, la corriente central-central representó el 18,95\% de los flujos totales. Después de iniciado el proceso de industrialización, debido a las limitaciones espaciales de Caracas, fue necesario reubicar las zonas industriales. Estados cercanos, como Aragua y Miranda, fueron áreas de expansión de la industria nacional. Las capitales de estos estados se convirtieron en el grupo de ciudades intermedias más próximas que permitieron la desconcentración industrial de la ciudad capital. Esto quizás explique el predominio de este flujo intrarregional.

Los flujos más intensos de emigrantes se iniciaron en las zonas con menor nivel de desarrollo. Las corrientes con mayor proporción de pérdidas de población fueron las siguientes: de la región nororiente a la región central, con una tasa de $-8,75$ por cada mil habitantes; de la región nororiente a la región oriente, con una tasa de $-6,84$ por mil, y de la región de Los Llanos a la región central, con una tasa de $-6,13$ por mil, flujos que por sus características y direccionalidad sugieren una migración de tipo rural-urbana. 


\section{Cuadro I}

\section{VENEZUELA: ESTRUCTURA DE LA MIGRACIÓNYTASAS DE MIGRACIÓN NETA ENTRE REGIONES, 1966-197 | a}

(En porcentajes del total de migrantes y número de migrantes por mil)

\begin{tabular}{|c|c|c|c|c|c|c|c|}
\hline \multirow{3}{*}{$\begin{array}{l}\text { Región de } \\
\text { origen }\end{array}$} & \multicolumn{6}{|c|}{ Estructura de la migración } & \multirow{3}{*}{ Total } \\
\hline & \multicolumn{6}{|c|}{ Región de destino } & \\
\hline & Central & Occidente & Los Llanos & Nororiente & Sur & Oriente & \\
\hline Central & 18,95 & 5,62 & 2,62 & 0,40 & 0,11 & 2,00 & 29,70 \\
\hline Occidente & 8,35 & 6,64 & 5,18 & 0,16 & 0,05 & 0,68 & 21,07 \\
\hline Los Llanos & 11,93 & 7,94 & 5,39 & 0,08 & 0,49 & 0,75 & 26,57 \\
\hline Nororiente & 3,33 & 0,39 & 0,19 & 0,06 & 0,01 & 3,12 & 7,09 \\
\hline Sur & $0,7 \mid$ & 0,23 & 0,93 & 0,01 & 0,04 & 0,09 & 2,02 \\
\hline Oriente & 5,98 & I,42 & 0,78 & 0,84 & 0,09 & 4,45 & 13,55 \\
\hline Total & 49,25 & 22,24 & 15,08 & 1,55 & 0,79 & 11,09 & 100 \\
\hline \multirow{3}{*}{$\begin{array}{l}\text { Región de } \\
\text { destino }\end{array}$} & \multicolumn{6}{|c|}{ Tasas de migración neta } & \multirow{3}{*}{ Total } \\
\hline & \multicolumn{6}{|c|}{ Región de origen } & \\
\hline & Central & Occidente & Los Llanos & Nororiente & Sur & Oriente & \\
\hline Central & - & 1,39 & 4,72 & I,48 & 0,30 & 2,02 & 9,92 \\
\hline Occidente & $-1,46$ & - & ।,47 & 0,12 & 0,10 & 0,39 & 0,62 \\
\hline Los Llanos & $-6,13$ & $-1,82$ & - & 0,07 & 0,29 & 0,02 & $-7,57$ \\
\hline Nororiente & $-8,75$ & $-0,70$ & $-0,31$ & & 0,02 & $-6,84$ & $-16,58$ \\
\hline Sur & $-5,05$ & $-|, 5|$ & $-3,77$ & $-0,05$ & - & $-0,00$ & $-10,38$ \\
\hline Oriente & $-4,85$ & $-0,89$ & $-0,03$ & 2,79 & 0,00 & - & $-2,99$ \\
\hline
\end{tabular}

Fuente: Tabulaciones especiales elaboradas sobre la base de los datos del $X$ Censo de Población y Vivienda de 1971.

a Los datos corresponden a la migración ocurrida en el quinquenio anterior a la realización del censo.

Aun cuando la movilidad desde áreas de bajo desarrollo fue predominante en términos de intensidad, la migración entre áreas de alto desarrollo también se mostró bastante voluminosa. El intercambio de personas entre las regiones occidente y central, en ambos sentidos, concentró el $14 \%$ de los movimientos totales registrados por el censo de 1971. Las ganancias netas de este intercambio favorecieron a la región central, que por cada mil habitantes sumó 1,4 personas procedentes de la región occidente.

Por último, las tasas netas muestran el peso relativo de las corrientes migratorias. En el período que va de 1966 a 1971 se observa que las regiones con mayor cantidad de pérdidas poblacionales fueron las regiones nororiente y sur, que registran tasas negativas de $-16,6$ por mil y $-10,5$ por mil, respectivamente. Por otra parte, las ganancias se concentraron en forma casi exclusiva en la región central, que por cada mil habitantes sumó una cifra aproximada de 10 migrantes.

\section{Los años setenta: la Gran Venezuela}

En 1968, el desarrollo industrial por sustitución de importaciones comenzó a mostrar claras señales de agotamiento. El proceso de industrialización se había orientado hacia la satisfacción de las necesidades del mercado 
interno, y este comenzaba a saturarse. Se hacía indispensable iniciar una nueva etapa de desarrollo que se dirigiera hacia los mercados externos y hacia la producción de bienes intermedios y de capital. Sin embargo, la baja productividad y las barreras proteccionistas impidieron a la industria venezolana traspasar las fronteras nacionales.

En 1974, Carlos Andrés Pérez asumió la presidencia de la República y en el V Plan de la Nación propuso orientar las acciones del Estado hacia la consolidación de una moderna economía de producción que sentara las bases de "la Gran Venezuela". Como consecuencia de la crisis energética mundial de 1973, originada por los conflictos en el Oriente Medio, el gobierno de Pérez tuvo la capacidad financiera para sostener su política económica.

El incremento de los precios del petróleo le generó al país cuantiosos ingresos fiscales, que fueron invertidos en la ampliación de las industrias básicas del Estado, la producción de bienes intermedios y de capital, la descentralización del desarrollo industrial y un oneroso presupuesto de obras públicas. En 1976, el gobierno ratificó su intención de conseguir el control integral de la industria estratégica nacional, y a finales de año nacionalizó los hidrocarburos y creó la empresa estatal que se encargaría de todas las operaciones petroleras nacionales: Petróleos de Venezuela (PDVSA).

El estímulo gubernamental creó las condiciones necesarias para iniciar una segunda fase en la sustitución de importaciones. Se instalaron grandes empresas de aluminio (estado de Bolívar) y se ampliaron las actividades siderúrgicas (estado de Bolívar), petroquímicas (estados de Carabobo y Zulia) y de refinería (estados de Anzoátegui, Carabobo, Falcón y Zulia), diversificando la capacidad productiva del país y favoreciendo la creación de nuevos empleos. Sin embargo, el financiamiento de esos proyectos se realizó recurriendo a múltiples empréstitos externos, que fueron acordados en el supuesto de una bonanza petrolera y en función de una hipotética producción futura (Melcher, 1992), forjándose una cuantiosa deuda externa.

La política económica estuvo acompañada de una estrategia oficial de ordenamiento territorial, que se definió ante la apremiante necesidad de desconcentrar la ciudad capital y la región central. El gobierno nacional estableció estímulos para la expansión de las actividades agrícolas, impulsó el sector de la construcción y creó mecanismos de atracción para que los nuevos proyectos industriales públicos o privados se localizaran en áreas prioritarias de desarrollo. Los traslados fueron dirigidos hacia cinco polos de desconcentración industrial: i) Oriente; ii) Occidente; iii) CentroOccidente; iv) Guayana, y v) Los Andes (Lucas, 2006). 


\section{Segundo momento: el panorama de la migración en el censo de 1981}

En 1979 se produjo el cambio de gobierno y en 1981 se llevó a cabo la operación censal, en la que se registró una población total de 14.516.571 habitantes. La información suministrada por el XI Censo de Población y Vivienda mostró un mayor volumen de movimientos territoriales. De acuerdo con los datos, 1.041 .179 personas declararon haber cambiado de residencia entre 1976 y 1981, lo que significa que al menos 7 de cada 100 personas habían experimentado un evento migratorio reciente dentro de los límites nacionales.

Las áreas hacia donde fueron dirigidas e impulsadas las actividades industriales en la década de 1970 (áreas oriente y occidente) pasaron a ser las regiones con mayores ganancias poblacionales. Lo que más sorprende es la ausencia de la región central como zona de atracción. Por su parte, las regiones nororiente y sur se mantuvieron como áreas de pérdida de población.

Mapa 3

\section{VENEZUELA: FLUJOS MIGRATORIOS INTERREGIONALES, I 98 I}

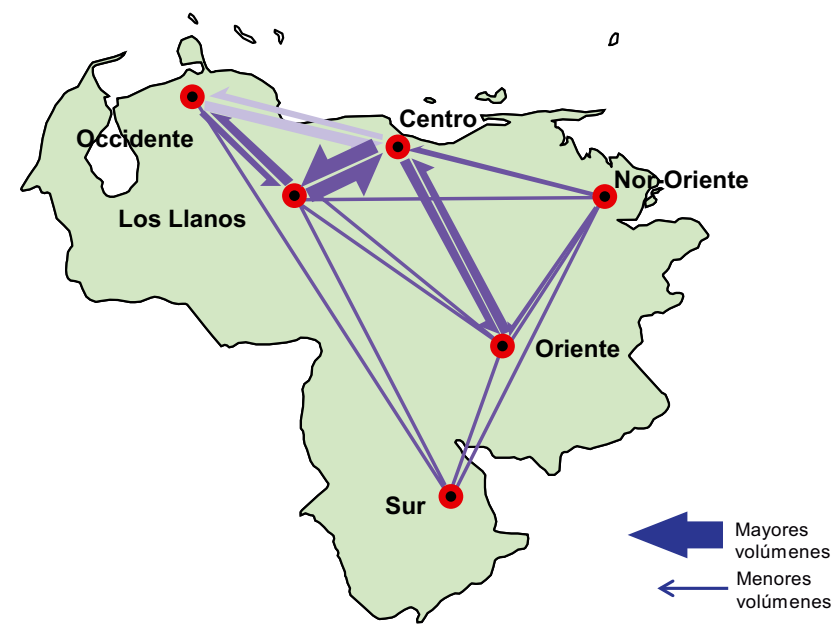

Fuente: Elaboración propia, sobre la base de los datos del XI Censo de Población y Vivienda de 1981.

La distribución de la migración interna (véase el cuadro 2) también puso en evidencia la pérdida de atracción de la región central, ya que la mayoría de las proporciones mostraron una variación negativa con respecto a 1971. Esta dinámica también se confirmó con las tasas de migración neta, que revelaron pérdidas para la región central de $-1,36$ por mil en los flujos con la región oriente y de $-1,30$ por mil con respecto a la región occidente. No obstante, la región central se mantuvo como la región que 
albergó mayor cantidad de inmigrantes, pues alrededor de 35 de cada 100 emigrantes eligieron esa región como lugar de destino, seguida de la región occidente, con un $23,8 \%$. Esta alta proporción se explica por el peso de la movilidad intrarregional.

\section{Cuadro 2}

\section{VENEZUELA: ESTRUCTURA DE LA MIGRACIÓNYTASAS DE} MIGRACIÓN NETA ENTRE REGIONES, $1976-1981^{\text {a }}$

(En porcentajes del total de migrantes y número de migrantes por mil)

\begin{tabular}{|c|c|c|c|c|c|c|c|}
\hline \multirow{3}{*}{$\begin{array}{l}\text { Región de } \\
\text { origen }\end{array}$} & \multicolumn{6}{|c|}{ Estructura de la migración } & \multirow{3}{*}{ Total } \\
\hline & \multicolumn{6}{|c|}{ Región de destino } & \\
\hline & Central & Occidente & Los Llanos & Nororiente & Sur & Oriente & \\
\hline Central & 14,98 & 8,19 & 6,56 & 1,32 & 0,22 & 6,32 & 37,60 \\
\hline Occidente & 5,44 & 5,99 & 5,44 & 0,14 & 0,08 & 1,46 & 18,56 \\
\hline Los Llanos & 8,32 & 7,81 & 5,77 & 0,11 & 0,49 & 1,39 & 23,89 \\
\hline Nororiente & 1,95 & 0,29 & 0,15 & 0,04 & 0,01 & 3,46 & 5,91 \\
\hline Sur & 0,65 & 0,25 & 1,10 & 0,01 & 0,09 & 0,16 & 2,26 \\
\hline Oriente & 3,44 & 1,23 & 0,82 & 1,16 & 0,11 & 5,02 & 11,79 \\
\hline Total & 34,78 & 23,76 & 19,86 & 2,79 & $\mid, 01$ & $|7,8|$ & 100 \\
\hline \multirow{3}{*}{$\begin{array}{l}\text { Región de } \\
\text { destino }\end{array}$} & \multicolumn{6}{|c|}{ Tasas de migración neta } & \multirow{3}{*}{ Total } \\
\hline & \multicolumn{6}{|c|}{ Región de origen } & \\
\hline & Central & Occidente & Los Llanos & Nororiente & Sur & Oriente & \\
\hline Central & & $-1,30$ & 0,83 & 0,29 & 0,20 & $-1,36$ & $-1,33$ \\
\hline Occidente & ।,38 & - & 1,18 & 0,07 & 0,08 & $-0,12$ & 2,60 \\
\hline Los Llanos & $-1,16$ & $-1,56$ & - & 0,03 & 0,40 & $-0,37$ & $-2,67$ \\
\hline Nororiente & $-1,97$ & $-0,47$ & $-0,13$ & - & 0,00 & $-7,28$ & $-9,84$ \\
\hline Sur & $-3,73$ & $-1,46$ & $-5,28$ & $-0,0$ I & - & $-0,42$ & $-|0,9|$ \\
\hline Oriente & 3,14 & 0,26 & 0,62 & 2,51 & 0,05 & - & 6,58 \\
\hline
\end{tabular}

Fuente: Tabulaciones especiales elaboradas sobre la base de los datos del XI Censo de Población y Vivienda de 1981.

a Los datos corresponden a la migración ocurrida en el quinquenio anterior a la realización del censo.

La dinámica de la expansión económica y la descentralización de la industria favorecieron a la región oriente, que se posicionó como la región con mayor ganancia de población, sumando casi 7 personas por cada mil habitantes, seguida por la región occidente, que agregó 2,6 por cada mil. La activación económica de la región oriente modificó los patrones nacionales de movilidad territorial y a partir de este quinquenio la región comenzó a mostrar un mayor peso dentro del panorama migratorio. Su capacidad de absorción de emigrantes se incrementó casi 7 puntos porcentuales entre 1971 y 1981.

\section{Los años ochenta: el gran viraje}

En 1979 Luis Herrera Campins asumió el poder, afirmando que recibía una "Venezuela hipotecada". Los desaciertos del gobierno anterior habían provocado la debacle de la inversión interna real y el incremento desmesurado de la deuda externa. La caída de los precios del petróleo en 1982 agravó la situación. Las restricciones económicas y la incapacidad 
de ahorro le impidieron a la nueva administración invertir en el sector industrial. Los recursos fueron orientados a gastos prioritarios asociados a las funciones sociales del Estado y el desarrollo nacional quedó paralizado. El modelo de sustitución de importaciones se había agotado.

La política de ordenamiento territorial tampoco resultó exitosa. A pesar de los esfuerzos gubernamentales de desconcentración poblacional y relocalización industrial, los desequilibrios regionales persistieron. La creación de polos de desarrollo, en el marco de la misma dinámica económica, reprodujo los problemas de absorción de recursos, crecimiento poblacional, marginalidad y pobreza propios de las grandes ciudades. En el VI Plan de la Nación, se insistió en las políticas de financiamiento de los sectores productivos regionales, como alternativa de desarrollo. No obstante, la crisis económica mermó los recursos públicos y este modelo proteccionista y centralista se volvió insostenible para el Estado. Así, cesaron los decretos de regionalización y comenzaron a desaparecer las corporaciones regionales (Ramírez Medina, 2002).

En 1981 se inició una incesante y creciente fuga de capitales, que condujo dos años más tarde al famoso "viernes negro". El 18 de febrero de 1983, el gobierno devaluó la moneda y estableció un fuerte régimen de control de cambios. En un país de importaciones, la devaluación se convirtió en sinónimo de pobreza. La nueva situación económica obligó a tomar ciertas medidas de austeridad en el gasto público y a recurrir a periódicas devaluaciones de la moneda para cubrir el déficit fiscal (Melcher, 1992). Al mismo tiempo, aumentaron el desempleo y el subempleo, y la situación de la población en general comenzó a mostrar rasgos críticos.

Con el regreso de Carlos Andrés Pérez a la presidencia del país en 1989, se desvaneció la doctrina centralista que había perdurado desde 1948 como mecanismo de organización del Estado y se planteó la redistribución de los poderes y la descentralización territorial.

Ante la recesión económica, la solución propuesta por el equipo de gobierno fue la aplicación de una serie de medidas neoliberales, sugeridas y orientadas por el Fondo Monetario Internacional (FMI). El "paquetazo liberal" - como se le conoció - incluía el término del régimen cambiario, la eliminación de restricciones en las tasas de interés, la disminución gradual de los subsidios del Estado y de los controles de precios, además del aumento del precio de los servicios públicos y de la gasolina (Arias Amaro, 2011). La inflación, la especulación, el estancamiento de los salarios y el descontento generalizado de la población generaron revueltas sociales e intentos de golpes de Estado, que funcionaron como mecanismos de presión para conseguir la destitución de Carlos Andrés Pérez en 1993. 


\section{Tercer momento: el panorama de la migración en el censo de 1990}

El censo de 1990 fue la fotografía de la crisis. La situación económica del país desestimuló muchas de las iniciativas industriales emprendidas durante la década de las "vacas gordas" (como suele llamarse al período de bonanza petrolera). El desarrollo nacional quedó paralizado y los problemas sociales comunes, como la pobreza y el desempleo, se intensificaron. En este contexto, se llevó a cabo el XII Censo de Población y Vivienda. De acuerdo con sus resultados, aunque la población en 1990 se había incrementado a 18.053.910 habitantes, el número de migrantes había disminuido; solo 941.288 personas declararon haber cambiado de lugar de residencia en los últimos cinco años, proporción que representa un 5,25\% de la población nacional de ese momento.

En el quinquenio que va de 1985 a 1990, los flujos mostraron una especie de equilibrio regional, en que se observan tres áreas de atracción y tres áreas de expulsión. La región que atrajo mayor número de migrantes - al igual que en el censo anterior - fue la región oriente, seguida de las regiones central y occidente. El desarrollo industrial y petrolero de la zona norte-costera a partir de los años setenta parece ser el factor impulsor de esta tendencia. Entre las regiones que perdieron población se encuentra la región de Los Llanos, que siguió siendo la que presentó una mayor pérdida, seguida de las regiones nororiente y sur.

\section{Mapa 4}

VENEZUELA: FLUJOS MIGRATORIOS INTERREGIONALES, 1990

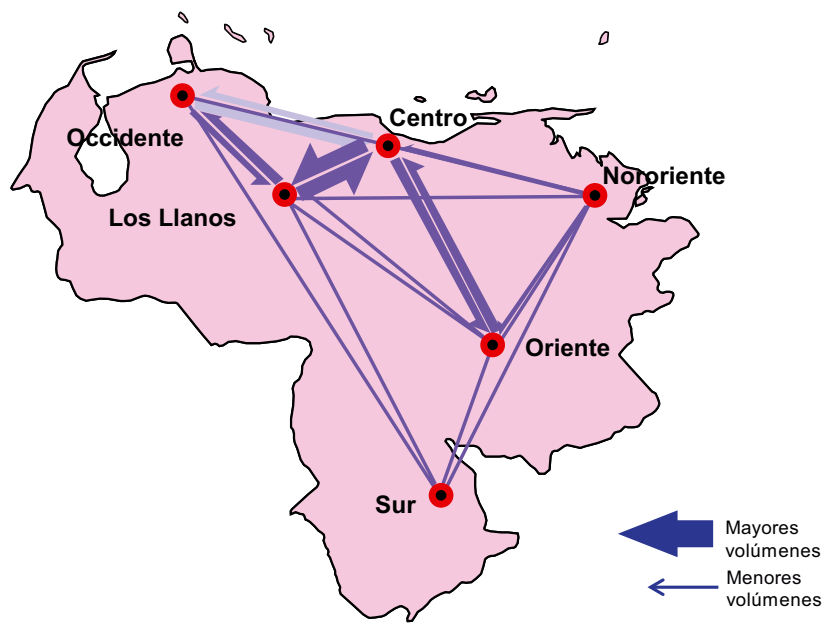

Fuente: Elaboración propia, sobre la base de los datos del XII Censo de Población y Vivienda de 1990. 
Los cambios coyunturales descritos también se reflejaron en la estructura de las migraciones internas. En el cuadro 3 se presenta la distribución de los movimientos producidos en este quinquenio. En principio, resalta la dinámica migratoria de la región central, que a diferencia de los censos anteriores mostró un incremento de los inmigrantes y una disminución de los emigrantes. Las regiones occidente y de Los Llanos mantuvieron proporciones similares en cuanto a recepción de emigrantes entre 1981 y 1990 . No obstante, la capacidad de atracción de la región occidente disminuyó 2 puntos porcentuales con respecto al censo anterior, al mismo tiempo que su proporción de emigrantes se incrementó. La región de Los Llanos no presentó grandes variaciones porcentuales intercensales.

\section{Cuadro 3}

VENEZUELA: ESTRUCTURA DE LA MIGRACIÓNYTASAS DE MIGRACIÓN NETA ENTRE REGIONES, I985-1990 a

(En porcentajes del total de migrantes y número de migrantes por mil)

\begin{tabular}{|c|c|c|c|c|c|c|c|}
\hline \multirow{3}{*}{$\begin{array}{l}\text { Región de } \\
\text { origen }\end{array}$} & \multicolumn{6}{|c|}{ Estructura de la migración } & \multirow{3}{*}{ Total } \\
\hline & \multicolumn{6}{|c|}{ Región de destino } & \\
\hline & Central & Occidente & Los Llanos & Nororiente & Sur & Oriente & \\
\hline Central & 15,49 & 6,46 & 5,78 & $|| \mid$, & 0,39 & 4,68 & 33,91 \\
\hline Occidente & 6,24 & 6,01 & 5,92 & 0,26 & 0,20 & 2,08 & 20,71 \\
\hline Los Llanos & 8,83 & 7,14 & 5,76 & 0,13 & 0,77 & $|, 8|$ & 24,44 \\
\hline Nororiente & 2,10 & 0,32 & 0,20 & 0,06 & 0,02 & 3,59 & 6,30 \\
\hline Sur & 0,64 & 0,27 & $|, 0|$ & 0,02 & 0,08 & 0,19 & 2,22 \\
\hline Oriente & 3,95 & 1,27 & 0,91 & 1,24 & 0,19 & 4,86 & 12,42 \\
\hline Total & 37,25 & 21,48 & 19,58 & 2,83 & 1,66 & $|7,2|$ & 100 \\
\hline \multirow{3}{*}{$\begin{array}{l}\text { Región de } \\
\text { destino }\end{array}$} & \multicolumn{6}{|c|}{ Tasas de migración neta } & \multirow{3}{*}{ Total } \\
\hline & \multicolumn{6}{|c|}{ Región de origen } & \\
\hline & Central & Occidente & Los Llanos & Nororiente & Sur & Oriente & \\
\hline Central & - & $-0,08$ & 1,13 & 0,37 & 0,10 & $-0,27$ & 1,24 \\
\hline Occidente & 0,08 & - & 0,42 & 0,02 & 0,02 & $-0,28$ & 0,27 \\
\hline Los Llanos & $-1,46$ & $-0,59$ & - & 0,03 & 0,12 & $-0,43$ & $-2,33$ \\
\hline Nororiente & $-2,39$ & $-0,16$ & $-0,17$ & - & $-0,01$ & $-5,68$ & $-8,40$ \\
\hline Sur & $-1,42$ & $-0,37$ & $-1,32$ & 0,02 & - & 0,01 & $-3,09$ \\
\hline Oriente & 0,56 & 0,62 & 0,69 & 1,80 & $-0,00$ & - & 3,66 \\
\hline
\end{tabular}

Fuente: Tabulaciones especiales elaboradas sobre la base de los datos del XII Censo de Población y Vivienda de 1990.

a Los datos corresponden a la migración ocurrida en el quinquenio anterior a la realización del censo.

Las tasas terminaron de dibujar el panorama migratorio en tiempos de crisis. En principio, la migración interna mostró una fuerte contracción; el impacto de los flujos disminuyó en casi todas las corrientes, con algunas excepciones. En el cuadro 3 se observa que en el quinquenio comprendido entre 1985 y 1990, la región central se posicionó nuevamente como la región más atractiva, pues más del $37 \%$ de los migrantes se dirigieron a ese destino. 
Las tasas de migración no variaron mucho con respecto a las del censo de 1981; solo reafirmaron la disminución de la intensidad migratoria. Las regiones nororiente, de Los Llanos y sur siguieron perdiendo población con respecto a la región central pero con una intensidad menor, en un rango entre $-1,42$ por mil y $-2,39$ por mil. Finalmente, con respecto a las corrientes, la región nororiente fue la que registró las mayores pérdidas, con una tasa de $-8,4$ por mil, mientras que la región oriente fue la que exhibió las mayores ganancias poblacionales, con una tasa de 3,7 por mil.

\section{Los años noventa: la transición}

En la década de 1990, la situación de crisis se agudizó. Durante el segundo gobierno de Rafael Caldera (1994-1999), el colapso del sector financiero comprometió aún más la recuperación del país. Ante la fuga de divisas se instauró un nuevo control de cambio. El gobierno presentó el programa de recuperación económica "Agenda Venezuela", también tutelado por el Fondo Monetario Internacional. El programa - del mismo tipo que el anterior- proponía la liberalización de la economía, los precios y el empleo, además de la privatización de las empresas nacionales. De esta manera, se vendió la Siderúrgica del Orinoco, se reformó el sistema de seguridad social, otorgando mayor participación a los servicios asistenciales privados, y se inició el plan de privatización parcial de Petróleos de Venezuela. El sector industrial también sufrió importantes contracciones; algunas empresas quebraron, mientras otras fueron desnacionalizadas.

En este contexto, Hugo Chávez Frías asumió la presidencia para el período 1999-2004. La reforma institucional del Estado se convirtió en una prioridad política del proyecto presentado por el líder venezolano. Luego de asumir el cargo, el presidente convocó a una Asamblea Nacional Constituyente, iniciando una primera fase de transición política que culminó con la consulta pública y la aprobación popular de la Constitución de la República Bolivariana de Venezuela, en 1999. La grave situación económica fue contrarrestada con un fortalecimiento de la política petrolera. El gobierno reconoció el carácter rentista de su economía y las dificultades que enfrentaba para desarrollar su proyecto político sin la pronta recuperación de los precios del petróleo. El equipo económico centró su estrategia en tres nodos centrales: i) la recuperación de los precios de los hidrocarburos; ii) el fortalecimiento de la Organización de Países Exportadores de Petróleo (OPEP), y iii) la paralización de los planes privatizadores de la industria nacional (Díaz Rangel, 2012). De esta manera, comenzó el proceso de reactivación económica del país, emprendiéndose un nuevo período de transformaciones sociales y políticas. 


\section{Cuarto momento: el panorama de la migración en el censo de 2001}

La década de 1990 transcurrió entre crisis económicas, el colapso financiero, la contracción de la actividad industrial, revueltas sociales y, al final, la transición hacia un nuevo régimen político. En este contexto, se realizó el primer censo del nuevo milenio y el decimotercero en la cuenta tradicional. Al año 2001, la migración en términos relativos había seguido disminuyendo. De un total de 23.054.210 habitantes censados, 1.108.862 habían sido parte del fenómeno migratorio; es decir, solo el 4,81\% de la población fue empadronada en una región diferente de aquella en que vivía en 1996.

De acuerdo con los datos del XIII Censo de Población y Vivienda, la migración interna pareció reconfigurarse, dejando en evidencia nuevos polos de atracción. Aun cuando se mantuvo un equilibrio entre las regiones donde se produjeron ganancias y pérdidas, la direccionalidad de los flujos cambió. Las zonas que a inicios del nuevo milenio habían ganado mayor cantidad de migrantes fueron las regiones oriente y occidente. Por primera vez la región de Los Llanos dejó de ser una zona de expulsión para convertirse en un área de atracción, mientras que la región central terminó de posicionarse como la franja con mayor volumen de pérdidas, sumándose a las regiones que tradicionalmente habían presentado ganancias netas negativas.

\section{Mapa 5 \\ REPÚBLICA BOLIVARIANA DE VENEZUELA: FLUJOS MIGRATORIOS INTERREGIONALES, 200 I}

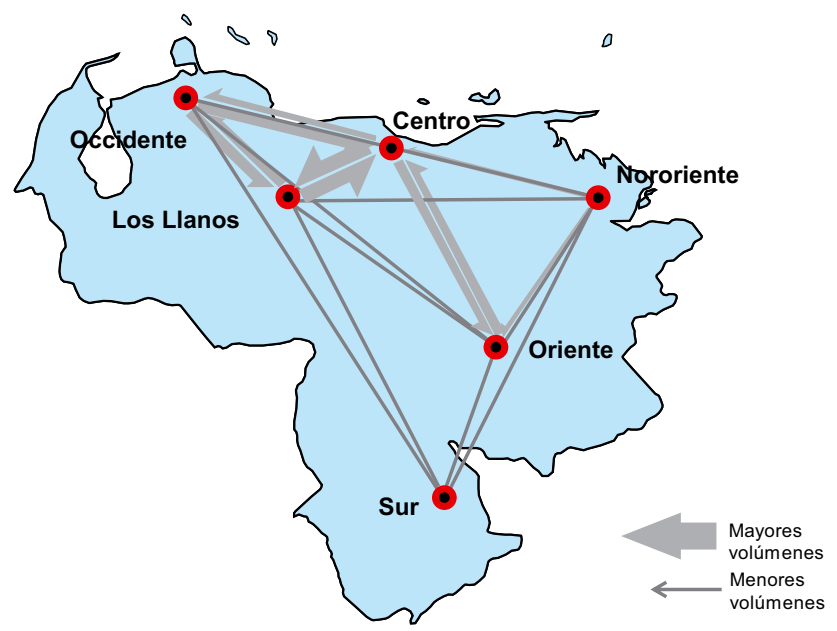

Fuente: Elaboración propia, sobre la base de los datos del XIII Censo de Población y Vivienda de 2001. 
En el cuadro 4 se muestra la estructura de la migración ocurrida entre 1996 y 2001. Lo que más llama la atención es el peso que alcanzó la proporción de inmigrantes que se trasladaron a la región de Los Llanos (22,6\% del total). Por primera vez — desde 1971— esta región sobrepasó los niveles de inmigración de la región occidente, ubicándose segunda después de la región central, cuya proporción de inmigrantes disminuyó casi 6 puntos porcentuales con relación al censo de 1990 .

\section{Cuadro 4 \\ REPÚBLICA BOLIVARIANA DE VENEZUELA: ESTRUCTURA DE LA MIGRACIÓNY TASAS DE MIGRACIÓN NETA ENTRE REGIONES, | 996-200 I a}

(En porcentajes del total de migrantes y número de migrantes por mil)

\begin{tabular}{|c|c|c|c|c|c|c|c|}
\hline \multirow{3}{*}{$\begin{array}{l}\text { Región de } \\
\text { origen }\end{array}$} & \multicolumn{6}{|c|}{ Estructura de la migración } & \multirow{3}{*}{ Tota } \\
\hline & \multicolumn{6}{|c|}{ Región de destino } & \\
\hline & Central & Occidente & Los Llanos & Nororiente & Sur & Oriente & \\
\hline Central & 17,75 & 6,93 & 7,37 & 0,97 & 0,46 & 6,56 & 40,04 \\
\hline Occidente & 4,21 & 5,03 & 6,74 & 0,16 & 0,23 & 2,78 & 19,15 \\
\hline Los Llanos & 6,19 & 6,83 & 5,79 & 0,13 & 0,85 & 2,57 & 22,35 \\
\hline Nororiente & 0,68 & 0,23 & 0,15 & 0,05 & 0,02 & 3,32 & 4,45 \\
\hline Sur & 0,49 & 0,26 & I,44 & 0,02 & 0,11 & 0,27 & 2,60 \\
\hline Oriente & 2,04 & 1,09 & 1,12 & ।,33 & 0,34 & 5,49 & $|1,4|$ \\
\hline Total & 31,37 & 20,36 & 22,62 & 2,66 & 2,00 & 20,99 & 100 \\
\hline \multirow{3}{*}{$\begin{array}{l}\text { Región de } \\
\text { destino }\end{array}$} & \multicolumn{6}{|c|}{ Tasas de migración neta } & \multirow{3}{*}{ Total } \\
\hline & \multicolumn{6}{|c|}{ Región de origen } & \\
\hline & Central & Occidente & Los Llanos & Nororiente & Sur & Oriente & \\
\hline Central & - & $-|, 0|$ & $-0,44$ & $-0,11$ & 0,01 & $-1,68$ & $-3,22$ \\
\hline Occidente & 0,83 & 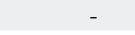 & 0,03 & 0,02 & 0,01 & $-0,52$ & 0,37 \\
\hline Los Llanos & 0,52 & $-0,04$ & - & 0,01 & 0,26 & $-0,64$ & 0,12 \\
\hline Nororiente & 0,72 & $-0,17$ & $-0,06$ & - & $-0,0$ I & $-4,93$ & $-4,45$ \\
\hline Sur & $-0,19$ & $-0,16$ & $-2,92$ & 0,02 & - & 0,33 & $-2,92$ \\
\hline Oriente & 2,88 & 1,08 & 0,93 & 1,27 & $-0,04$ & - & 6,12 \\
\hline
\end{tabular}

Fuente: Tabulaciones especiales elaboradas sobre la base de los datos del XIII Censo de Población y Vivienda de 2001.

a Los datos corresponden a la migración ocurrida en el quinquenio anterior a la realización del censo.

En el caso de la emigración, se observó un incremento considerable de la proporción de personas que reemplazaron a la región central como lugar de residencia: en diez años el porcentaje creció del 33,9\% al $40 \%$ del total de emigrantes. Por su parte, los porcentajes de emigrantes de las regiones de Los Llanos y occidente disminuyeron con respecto al censo de 1990. Las proporciones más bajas de movilidad territorial se mantuvieron en las regiones con menores niveles del IDH.

Las tasas de migración confirman las nuevas tendencias. La región central dejó de ser atractiva como destino y mostró tasas negativas en su relación con casi todas las regiones, excepto la sur. La región nororiente fue aquella donde se produjo la mayor pérdida de población, que llegó a $-4,5$ por mil habitantes, seguida por la región central, con una tasa neta 
de $-3,22$ por mil. La región que recibió mayores ganancias de población siguió siendo la región oriente, donde se registró incluso un incremento con respecto al quinquenio anterior.

\section{Enlazando hechos, números y teorías ${ }^{3}$}

La migración es un tipo de respuesta social que surge ante ciertos condicionantes económicos. La premisa básica del fenómeno migratorio es que las personas buscan trasladarse desde un lugar con oportunidades limitadas hacia otro en que — según perciben - podrán desarrollar al máximo sus potencialidades y mejorar sus condiciones de vida. Aunque en este principio se acepta la migración como el acto racional de una persona individual, también implícitamente se reconoce la existencia de disparidades estructurales dentro de la configuración de los territorios nacionales.

En las teorías clásicas se asocia la migración a procesos de modernización diferenciados. La desigual expansión de los complejos industriales propicia el desarrollo de ciertos espacios geográficos en detrimento de otros. En el caso de la República Bolivariana de Venezuela, el desarrollo industrial estuvo intrínsecamente ligado a la explotación de hidrocarburos. Aparte de la capital, las primeras ciudades se establecieron en función de su participación en la economía petrolera, delineándose así la jerarquía del sistema urbano dentro del país. Igualmente, las políticas adoptadas por los gobiernos desde la visión del Estado paternalista, dirigidas hacia el incentivo y la difusión de las industrias nacionales en áreas específicas, terminaron de alinear la estructura urbana nacional.

Nuestra historia se inicia en los años sesenta. El impulso dado a la industria por el Estado proteccionista durante la década propició nuevas modalidades de distribución de la población. En términos regionales, en el quinquenio comprendido entre 1966 y 1971, las regiones central y occidente - las zonas de mayor concentración industrial— se posicionaron como las áreas más atractivas; las personas llegaban desde las regiones que presentaban las condiciones más precarias: nororiente, Los Llanos, sur y oriente.

Los flujos iniciados desde la región mayormente agropecuaria (Los Llanos) fueron los más cuantiosos. La región con mayor proporción de pérdidas de población fue la nororiente, un área históricamente rezagada. Personas jóvenes, sobre todo mujeres, fueron las que más se movilizaron hacia los destinos más desarrollados, una característica típica de la movilidad campo-ciudad. La alta migración femenina suele explicarse por

3 En este artículo se recoge parte de una investigación mucho más amplia. En esta sección se emplearon algunos datos estadísticos procesados en la versión original. 
la baja productividad de las mujeres en las actividades agrícolas (Muñoz y De Oliveira, 1972) y por la posibilidad que brinda la ciudad de insertarse en actividades domésticas y de servicios.

La migración entre áreas urbanas también tuvo cabida durante este período, en especial entre las regiones central y occidente. Sin embargo, mientras que el flujo de la región central a la región occidente fue principalmente masculino, el flujo inverso, de la región occidente a la región central, mostró una ligera superioridad de mujeres emigrantes. La mayor movilidad de los hombres es una característica de la migración urbana-urbana, que suele explicarse por la menor participación femenina dentro de las actividades productivas (Chávez Galindo, 1999). Por lo tanto, estos datos sugieren que en 1971, en tanto que la región central ya expulsaba personas hacia los parques industriales en expansión, la región occidente todavía mantenía una movilidad más bien de tipo rural-urbana.

En la década de 1970 se produjo el efecto favorable del increíble auge de los precios del petróleo. Los cuantiosos ingresos fueron invertidos en la segunda etapa de la industrialización por sustitución de importaciones, destinada específicamente a bienes intermedios y de capital. En 1976 se nacionalizó el petróleo, lo que significó el control absoluto de todas las actividades petroleras nacionales y sus respectivas ganancias.

Por su parte, la alta concentración de población y de industrias en la zona centro-norte del país comenzó a representar un problema. Entre 1974 y 1978 se promulgaron diferentes decretos de ordenación territorial, mediante los cuales se restringieron los establecimientos industriales en la Zona Metropolitana de Caracas. La estrategia de desconcentración fue diseñada a partir de la teoría de los polos de crecimiento. El Estado nacional estimuló la activación de cinco polos de desarrollo, que en términos de la regionalización definida en este estudio, se reducen a: i) Región oriente: estados de Anzoátegui y Bolívar; ii) Región occidente: estados de Zulia, Lara y Falcón, y iii) Región de Los Llanos, con solo una entidad, Táchira.

Esta política de reorganización económico-territorial transformó las corrientes de migración interna, reafirmando la asociación positiva que existe entre política estatal, desarrollo económico y movilidad territorial. Durante el quinquenio que va de 1976 a 1981, las regiones que presentaron corrientes netas positivas fueron oriente y occidente, áreas de activación económica. Ambas recibieron un importante contingente de personas procedentes de la región central; del total de emigrantes del estado de Aragua, el estado Bolivariano de Miranda y el Distrito Capital, casi el $40 \%$ se movilizó hacia dichas regiones. 
Junto con esta intensa movilidad, los nuevos polos de desarrollo se convirtieron en las zonas de atracción de aquellas áreas rezagadas de los procesos de transformación económica. La proximidad en términos de distancia primó en estos movimientos. Así, la migración rural-urbana persistió, pero con nuevos escenarios: la región oriente acogió 2,5 personas procedentes de la región nororiente por cada mil habitantes, mientras que la región occidente recibió migrantes de Los Llanos, a una tasa de 1,18 por mil.

La década de 1980 estuvo signada por la crisis. Los precios del petróleo cayeron notoriamente, afectando la economía nacional. Las restricciones monetarias frenaron la producción industrial, desalentando el desarrollo e incrementando los problemas sociales. Las críticas a las prácticas proteccionistas se multiplicaron y el Estado, presionado por la situación de crisis, transformó su política. De esta manera, cesaron los decretos de regionalización, se paralizó el financiamiento de la industria y desaparecieron las corporaciones regionales. El resultado fue la disminución de la mayoría de los flujos migratorios. Esto confirma que no solo la adopción de políticas puede modificar el estado de las cosas; también su ausencia o el hecho de que sean desincentivadas puede alterar la estructura social.

En el quinquenio comprendido entre 1985 y 1990, la región central volvió a integrar el grupo de las áreas con ganancias netas positivas, junto con las regiones oriente y occidente. Sin embargo, los datos demuestran que la direccionalidad de los flujos no varió tanto como la intensidad. Las tasas de migración neta de las corrientes iniciadas en la región central con destino hacia las regiones oriente $u$ occidente disminuyeron considerablemente, en relación con el censo anterior. Esto sugiere que la posición ventajosa de la región central durante este período no se debió a un incremento de su atractivo, sino más bien a una recesión de la emigración.

La migración rural-urbana también se redujo, pero no en las mismas proporciones. La región oriente continuó ganando población del nororiente, y la región occidente sumando personas de Los Llanos, pero con una variación de las tasas netas de migración de apenas $-0,7$ por mil y $-0,8$ por mil, respectivamente, en relación con el censo de 1981. Por su parte, en la región central la ganancia de personas procedentes de Los Llanos aumentó 0,3 por mil, con respecto al levantamiento anterior. De acuerdo con estos datos, en períodos de recesión la migración entre áreas urbanas tiende a disminuir a un ritmo más intenso que la migración campo-ciudad.

En la década de 1990, la crisis económica persistió. El sector financiero colapsó y la industria sufrió importantes contracciones. Igualmente, se inició una política de privatización de las empresas 
nacionales, que fue frenada por el presidente Hugo Chávez Frías después de las elecciones de 1998. La asociación de PDVSA con transnacionales petroleras, para la explotación de la Faja Petrolífera del Orinoco - la fuente de reservas de hidrocarburos líquidos más grande del mundo- fue una de las mayores acciones de la política liberal. A pesar de ello, la activación económica de esta industria en el oriente del país tuvo su impacto en los patrones de movilidad territorial.

En el quinquenio comprendido entre 1996 y 2001, las regiones oriente y occidente permanecieron como zonas de ganancias poblacionales, la región de Los Llanos por primera vez se ubicó entre las áreas de atracción y la región central retomó su condición de zona de expulsión. La mayor cantidad de migrantes que ganó la región oriente, en términos de migración neta, provino de la región central. La migración fue predominantemente masculina. Del total de personas que siguieron la corriente central-oriente, un 37,4\% cambió su residencia hacia Anzoátegui y un 24,7\% hacia Monagas. La Faja Petrolífera del Orinoco, ubicada al sur de los estados de Guárico, Anzoátegui y Monagas, al parecer fue el motor de atracción de esta región. En síntesis, el tipo de movilidad observado entre las regiones central y oriente fue sobre todo urbano y estuvo asociado a la diversificación económica de la región oriente, resultante de la activación del eje petrolero.

La región llanera también sumó mayor cantidad de población procedente del centro. Aunque en esta región predominan las actividades agropecuarias, esta tendencia definitivamente no corresponde a un tipo de migración urbano-rural. Los migrantes procedentes de la región central fueron en su mayoría hombres de entre 20 y 34 años de edad, que eligieron como destinos principales los estados de Guárico (20,5\%), Táchira (20\%) y Mérida $(13,2 \%)$. Guárico es parte de la Faja Petrolífera del Orinoco, Táchira es el estado más industrializado de la zona andina del país y Mérida presenta un alto desarrollo tecnológico, impulsado por la Universidad de Los Andes. Por lo tanto, la movilidad que se produjo entre las regiones central y de Los Llanos fue esencialmente urbana.

La migración rural-urbana también pudo apreciarse en el censo de 2001, específicamente entre las regiones de menor nivel del índice de desarrollo humano. No obstante, su intensidad fue mucho menor que en años anteriores. La región sur perdió 0,19 personas por cada mil habitantes con respecto al centro. La región nororiente perdió 4,93 personas por mil con respecto a la región oriente y ganó 0,72 personas por mil con respecto a la región central. Los movimientos en estas direcciones fueron predominantemente femeninos. Mención aparte requiere el flujo de la región sur a la región de Los Llanos, cuya tasa de migración por sexo 
favoreció a los hombres. Analizando esta corriente un poco más de cerca, se observa que el 92,39\% de los movimientos se iniciaron en Barinas y tuvieron como destino los estados de Táchira, Portuguesa y Mérida, lo que parece indicar que se trata de movimientos urbanos entre ciudades intermedias.

\section{E. Consideraciones finales}

Este análisis evolutivo de los procesos de movilidad territorial a través de los censos de población y vivienda permitió precisar tres tendencias generales del proceso migratorio venezolano a lo largo del tiempo: i) disminución de la intensidad de la migración interna a nivel nacional; ii) pérdida de importancia de la migración rural-urbana, junto con un incremento de la movilidad de ciudad a ciudad, y iii) cambio del patrón de migración tradicional, que implica moverse desde áreas de bajo desarrollo hacia zonas de alto desarrollo.

Después de los años cincuenta, se inició en Venezuela un acelerado proceso de urbanización. En 2001, se estimó que un $87,7 \%$ de la población total habitaba centros poblados con más de 2.500 habitantes. Ese mismo año, las regiones más desarrolladas (central, occidente y oriente) exhibían proporciones de población urbana superiores al 90\%, mientras que la región con mayor población rural (sur) mostraba una cifra de apenas un $30 \%$. En ese contexto de urbanización, resultan prácticamente inoperantes las categorías de disparidad territorial en los términos clásicos que empleó Lewis en los años cincuenta, como sectores tradicionales de subsistencia (rurales) y sectores modernos capitalistas (urbanos) (Lewis, 1954).

La homogeneidad del territorio nacional en términos de urbanización parece ser la causa principal de la disminución gradual de la intensidad de la migración interna en la República Bolivariana de Venezuela. En un país donde la proporción total de población rural alcanza apenas un 11,6\% (2001), la movilidad campo-ciudad no puede ser predominante. Sin embargo, este aparente equilibrio sectorial, aunque redujo la intensidad del fenómeno, no anuló la migración interna — como algunos teóricos clásicos hubiesen podido esperar - sino que más bien impulsó nuevas tendencias migratorias. Esto lleva a preguntarse: ¿Qué hace que se mantenga la movilidad territorial dentro de los territorios nacionales? ¿Qué tipo de dinámica económica está primando en las ciudades que potencia los movimientos entre áreas urbanas?

Aunque sobre la base de los datos no es posible llegar a respuestas certeras sobre este asunto, la teoría nos brinda algunas aproximaciones. Stark (1991) expresa que la migración es un medio que permite reducir niveles de insatisfacción. Las ciudades han evolucionado de manera 
diferenciada según su posición geográfica, su principal rama económica, los incentivos gubernamentales y el nivel de desarrollo tecnológico, entre otros factores, como resultado de los cuales los desequilibrios regionales se trasladan hacia los entornos urbanos. Dichas disparidades continúan generando sentimientos de inconformidad y frustración en muchos hogares, cuyos miembros, al compararse con otros económicamente mejor posicionados, nutren esa sensación de privación relativa que - de acuerdo con el autor- es lo que incrementa las probabilidades de iniciar un movimiento migratorio $y$, por tanto, pudiera ser la causa de que se mantengan los cambios residenciales a través del tiempo.

Las desigualdades socio-territoriales, en términos modernos, se pusieron de manifiesto con el índice de desarrollo humano, sobre la base del cual fue posible visualizar el territorio nacional en función del horizonte de oportunidades que cada región ofrece para el máximo aprovechamiento de las capacidades individuales. De acuerdo con esta clasificación, cabría esperar - aun cuando no prime la movilidad rural-urbana- que los movimientos se verifiquen desde zonas de menor desarrollo hacia otras de mayor desarrollo. Lo que sorprende en el caso de la República Bolivariana de Venezuela, es que esta tendencia no se cumplió en la mayoría de los casos. Lo que los datos revelaron fue que una región con muy alto nivel de desarrollo humano (la región central), desde los años ochenta estuvo expulsando población hacia áreas de alto y medio desarrollo humano. ¿Qué puede explicar este comportamiento?

Las políticas de desconcentración dirigidas hacia la zona centro-norte costera del país, aunadas a la nueva dinámica económica internacional, quizás brinden algunas luces sobre esta tendencia. Inicialmente, el Estado impulsó estrategias de dispersión industrial con la idea de descongestionar el eje central del país. Sin embargo, los cambios en el modelo económico mundial terminaron por alentar este proceso. El fortalecimiento de la interdependencia entre las naciones - propia del mundo globalizado- y el debilitamiento de lo nacional como unidad espacial predominante impulsaron el surgimiento de nuevos patrones de organización geográfica, siendo las áreas metropolitanas el primer indicio de esta reconfiguración territorial.

En el caso de Caracas, el proceso de urbanización, aunque se inició de manera tardía, avanzó con creces, gracias a su velocidad. La expansión de la ciudad capital llegó incluso a traspasar los límites del estado Bolivariano de Miranda, gestándose así la primera área metropolitana del país. Desde los años setenta, ya se venía reduciendo la participación del Distrito Federal en la producción industrial del país, al mismo tiempo que se congregaban allí las sedes sociales y comerciales de las principales empresas nacionales. 
Esta dinámica siguió potenciándose hasta que el Área Metropolitana de Caracas logró ajustarse a las exigencias de los mercados globalizados, consolidándose como una metrópoli de servicios, donde actualmente se concentran sedes gerenciales de grandes empresas, de servicios avanzados y del sector financiero (Barrios, 2008).

En medio de este contexto, en 2001 la región central se ubicó entre las áreas expulsoras de población, lo que evidenció tres claras tendencias: i) alta migración intrarregional; ii) tasas de emigración moderadas hacia áreas de desarrollo humano alto, y iii) tasas de emigración moderadas hacia áreas de desarrollo medio. La migración entre los cuatro estados que conforman la región central alcanzó la cifra más alta, 6,6 migrantes intrarregionales por cada mil habitantes. Este dato refleja un primer atributo de la dinámica global, la desconcentración concentrada, es decir, el hecho de que, en el marco de la conformación de las ciudades globales y las megarregiones, la emigración comienza a orientarse hacia zonas colindantes con el centro económico principal (Rodríguez, 2008); el estado Bolivariano de Miranda, limítrofe con el Distrito Capital, absorbió el 60,4\% de todos los movimientos de la región y el 49,5\% de los emigrantes de la ciudad capital.

Por su parte, la emigración desde la región central hacia la región occidente — de alto desarrollo humano- mostró una tasa de 2,6 personas por mil, al mismo tiempo que del total de migrantes que partieron desde la región central, el 52\% fue acogido por el estado de Carabobo. Estos datos sugieren una alta movilidad entre el Distrito Capital, el estado Bolivariano de Miranda y los estados de Aragua, Carabobo y Vargas, entidades que, de acuerdo con Barrios (2008), conforman una megalópolis de tipo axial que unifica los dos puertos más importantes del país (pág. 30). De acuerdo con la teoría de la ciudad global, la nueva geografía urbana, junto con las modernas redes de transporte, vitaliza los parques científicos, económicos y administrativos de la megarregión, además de los mercados de consumo, propiciando la movilidad de bienes y personas entre las áreas metropolitanas que la conforman. Esta moderna dinámica quizás sea la clave para entender la movilidad urbana-urbana entre áreas con altos niveles de desarrollo humano.

Sin embargo, estas constelaciones también han venido estableciéndose en conjunto con un proceso de deterioro de la calidad de vida en las grandes ciudades. El incremento de las desigualdades territoriales, económicas y sociales que mantienen una marcada segmentación interna, junto con el aumento del desempleo, la saturación, la segregación residencial, la inseguridad y la violencia, también son factores que pueden estar incidiendo en los procesos de movilidad territorial, específicamente en la migración desde zonas de alto desarrollo hacia otras con niveles medios. 
En el quinquenio que va de 1996 a 2001, al menos 2,7 personas por cada mil habitantes cambiaron su residencia desde la región central hacia la región de Los Llanos. Esta migración — como ya se mencionófue estrictamente urbana. Las facilidades de movilidad interregional que permiten las modernas vías de comunicación, las oportunidades económicas que brindan las ciudades que recién inician su ciclo de urbanización y los beneficios residenciales que pueden ofrecer las ciudades intermedias probablemente están incidiendo en la consolidación de este flujo, que se muestra como una alternativa a las secuelas perversas del gigantismo urbano.

\section{Bibliografía}

Arias Amaro, A. (2011), Lecciones de historia moderna y contemporánea de Venezuela, Caracas, Romor.

Barrios, S. (2008), Metropolización y desigualdades socio-territoriales en Venezuela, Caracas, Fondo de Población de Naciones Unidas (UNFPA).

Bolívar Cholett, M. (1994), Población y sociedad en la Venezuela del siglo XX, Caracas, Fondo Editorial Tropikos.

Chávez Galindo, A. M. (1999), La nueva dinámica de la migración interna en México de 1970 a 1990, Cuernavaca, Centro Regional de Investigaciones Multidisciplinarias de la Universidad Nacional Autónoma.

Díaz Rangel, E. (2012), "La política petrolera en la Venezuela Bolivariana" [en línea] http://www.aporrea.org/energia/a137962.html.

Duharte Díaz, E. (2006), “Los sistemas políticos: algunas reflexiones conceptuales”, Teoría y procesos políticos contemporáneos, La Habana, Félix Varela.

El-Shakhs, S. (1972), "La alta primacía: desarrollo, primacía y sistema de ciudades", ¿Descentralización o desarticulación urbana?, J. Camas, México, D.F., Centro de Investigaciones y Estudios Superiores en Antropología Social (CIESAS)-Instituto Mora.

Freitez, A. (1988), La migración interna en Venezuela (1920-1981): tres periodos para su análisis, Caracas, IIES-Universidad Católica Andrés Bello (UCAB).

Fundación Polar (2000), Historia de Venezuela en imágenes, Caracas.

Geyer, H. (1996), "Expanding the theoretical foundation of the concept of differential urbanization", Tijdschrift voor Economische en Sociale Geografie, vol. 87, № 1.

Geyer, H. y T. Kontuly (1993), "A theoretical foundation for the concept of differential urbanization", International Regional Science Review, vol. 17, № 2.

González Tachiquin, M. (2005), "El estudio de las políticas públicas: un acercamiento a la disciplina", Quid Juris, vol. 2, No 1.

Hermansen, T. (1977), "Polos y centros de desarrollo en el desarrollo nacional y regional: elementos de un marco teórico", Polos y centros de crecimiento en la planificación regional, A. Kuklinski, México, D.F., Fondo de Cultura Económica.

Lahera, E. (2002), Introducción a las políticas públicas, México, D.F., Fondo de Cultura Económica.

Lee, E. (1975), "Una teoría de las migraciones”, Migraciones internas: teoría, método y factores sociológicos, J. Elizaga y J. Macisco, Santiago de Chile, Centro Latinoamericano y Caribeño de Demografía (CELADE). 
Lewis, A. (1954), "Economic development with unlimited supplies of labour", The Manchester School, № 22.

Lucas, G. (2006), Industrialización contemporánea en Venezuela: política industrial del Estado venezolano 1936-2000, Caracas, Universidad Católica Andrés Bello.

Mascareño, C. (ed.) (2003), Políticas públicas, Siglo XXI. Caso venezolano, Caracas, Centro de Estudios del Desarrollo (CENDES).

Melcher, D. (1992), "La industrialización de Venezuela", Economía, № 10.

Meny, I. y J. C. Thoenig (1992), Las políticas públicas, Barcelona, Ariel.

Muñoz, H. y O. De Oliveira (1972), "Migraciones internas en América Latina: exposición y crítica de algunos análisis", Migración y desarrollo, Buenos Aires, Consejo Latinoamericano de Ciencias Sociales (CLACSO).

Partida, V. (2011), Migración. Notas de clase, México, D.F.

PNUD (Programa de las Naciones Unidas para el Desarrollo) (1990), Informe sobre Desarrollo Humano, 1990, Bogotá, Tercer Mundo Editores.

Presidencia de la República Bolivariana de Venezuela (2006), "Proyecto Nacional Simón Bolívar. Primer Plan Socialista -PPS-: Desarrollo Económico y Social de la Nación 2007-2012", Centro Nacional de Desarrollo e Investigación en Telecomunicaciones [en línea] http://www.cendit.gob.ve/uploaded/pdf/Proyecto_Nacional_Simon_Bolivar.pdf.

Rodríguez, J. (2008), "Distribución espacial, migración interna y desarrollo", Revista de la CEPAL, No 96 (LC/G.2396-P), Santiago de Chile, Comisión Económica para América Latina y el Caribe (CEPAL).

(2004), "Migración interna en América Latina y el Caribe: estudio regional del período 1980-2000”, serie Población y Desarrollo, No 50 (LC/L.2059-P), Santiago de Chile, Comisión Económica para América Latina y el Caribe (CEPAL).

Rodríguez, J. y G. Busso (2009), "Migración interna y desarrollo en América Latina entre 1980 y 2005", Libros de la CEPAL, № 102 (LC/G.2397-P), Santiago de Chile, Comisión Económica para América Latina y el Caribe (CEPAL). Publicación de las Naciones Unidas, $\mathrm{N}^{\circ}$ de venta: S.09.II.G.14.

Sassen, S. (2007), "El reposicionamiento de las ciudades y regiones urbanas en una economía global: ampliando las opciones de política y gobernanza", Eure, vol. XXXIII, № 100. (2000), "The global city: strategic site/new frontier", American Studies, № 2-3. (1995), "La ciudad global: introducción a un concepto", Brown Journal of World Affairs, vol. XI, № 2 .

Singer, P. (1975), Economía Política de la Urbanización, Madrid, Siglo XXI Editores.

Sobrino, J. (2010), Migración interna en México durante el siglo XX, México, D.F., Consejo Nacional de Población (CONAPO).

Stark, Oded (1984), "Migration decision making: a review article", Journal of Development Economics, vol. 14, № 1 .

(1991), The Migration of Labor, Cambridge, Basil Blackwell.

Suárez, M. y R. Torrealba (1979), "Internal migration in Venezuela", Urban Anthropology, vol. VIII, $\mathrm{N}^{\mathrm{o}} 3 / 4$.

White, M. y D. Lindstrom (2005), "Internal migration”, Handbook of Population, D. Poston y M. Micklin, Nueva York, Kluwer Academia/Plenum Publishers.

Zelinsky, W. (1971), "La hipótesis de la transición de la movilidad”, ¿Descentralización o desarticulación urbana?, J. Camas, México, D.F., Centro de Investigaciones y Estudios Superiores en Antropología Social (CIESAS)-Instituto Mora. 


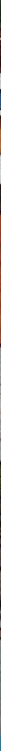

